\title{
Know Your Noodles! Assessing Variations in Sodium Content of Instant Noodles across Countries
}

\author{
Clare Farrand 1,*, Karen Charlton 2,3, Michelle Crino ${ }^{1}$, Joseph Santos ${ }^{1}$, \\ Rodrigo Rodriguez-Fernandez ${ }^{4}$, Cliona Ni Mhurchu ${ }^{5}$ and Jacqui Webster ${ }^{1}$ \\ 1 The George Institute for Global Health, The University of New South Wales, P.O. Box M20 Missenden Rd, \\ Sydney 2006, Australia; mcrino@georgeinstitute.org.au (M.C.); jsantos@georgeinstitute.org.au (J.S.); \\ jwebster@georgeinstitute.org.au (J.W.) \\ 2 School of Medicine, Faculty of Science, Medicine and Health, University of Wollongong, Wollongong 2522, \\ Australia; karen_charlton@uow.edu.au \\ 3 Illawarra Health and Medical Research Institute, Building 32, University of Wollongong Campus, \\ Wollongong 2522, Australia \\ 4 Non-Communicable Diseases, International SOS, NCD Asia Pacific Alliance, Chiswick Park, \\ 566 Chiswick High Rd, Chiswick, London W4 5YE, UK; rod.rodriguez@ncdapa.org \\ 5 National Institute for Health Innovation, University of Auckland, Private Bag 92019, Auckland Mail Centre, \\ Auckland 1142, New Zealand; c.nimhurchu@auckland.ac.nz \\ * Correspondence: cfarrand@georgeinstitute.org.au; Tel.: +61-2-8052-4541
}

Received: 11 April 2017; Accepted: 8 June 2017; Published: 16 June 2017

\begin{abstract}
Reducing salt intake is a cost-effective public health intervention to reduce the global burden of non-communicable disease (NCDs). Ultra-processed foods contribute $\sim 80 \%$ of dietary salt in high income countries, and are becoming prominent in low-middle income countries. Instant noodle consumption is particularly high in the Asia Pacific region. The aim of this study was to compare the sodium content of instant noodles sold worldwide to identify potential for reformulation. Analysis was undertaken for 765 instant noodle products from 10 countries using packaged food composition databases of ultra-processed foods compiled by the Global Food Monitoring Group (GFMG) and national shop survey data. Sodium levels were high and variable, within and between countries. Instant noodles in China had the highest mean sodium content (1944 mg/100 g; range: 397-3678/100 g) compared to New Zealand (798 mg/100 g; range: 249-2380 mg/100 g). Average pack size ranged from $57 \mathrm{~g}$ (Costa Rica) to $98 \mathrm{~g}$ (China). The average packet contributed $35 \%$ to $95 \%$ of the World Health Organization recommended daily salt intake of $<5 \mathrm{~g}$. Forty percent of products met the Pacific Island (PICs) regional sodium targets, 37\% met the South Africa 2016 targets, and $72 \%$ met the UK 2017 targets. This study emphasises a need for stronger regulation and closer monitoring to drive rigorous reformulation of salt in ultra-processed foods.
\end{abstract}

Keywords: salt; sodium; salt reduction; ultra-processed food; instant noodles; blood pressure; non-communicable disease (NCDs); burden of disease; nutrition transition; regulation; salt targets

\section{Introduction}

Cardiovascular disease (CVD) is the number one cause of death worldwide [1], responsible for 17.5 million deaths in 2012. High salt intake raises blood pressure, a major risk factor for CVD. Reducing population salt intake is recognised as a "best buy" for prevention and control of non-communicable diseases (NCDs) by lowering blood pressure and reducing risk of strokes and heart disease [2]. Salt reduction is considered a priority intervention by the World Health Organization (WHO) due to its high feasibility and potential to benefit to the whole population. Many countries are working 
towards achieving the global target of a $30 \%$ relative reduction in mean population salt intake by 2025 , towards the WHO recommendation of $<5 \mathrm{~g} /$ day [3].

Salt is a cheap food ingredient and ubiquitous in the food supply [4]. Salt is added to food products for the purposes of taste and preservation, and to improve technological processes [5]. In most high income countries, the majority of salt in the diet is from ultra-processed foods [6]. Thus, reformulation efforts to reduce the amount of salt added to ultra-processed foods are paramount to reduce population level salt intake. In general, in many low-middle income countries, the major source of salt in the diet is table salt and condiments added during cooking or at the table [6]. However, these countries are increasingly undergoing urbanisation and are experiencing a nutrition transition that is characterised by a marked change in food consumption patterns and a notable shift towards consumption of more ultra-processed foods $[7,8]$.

A key example of this is instant noodles; an ultra-processed ultra-processed food product which is widely available at a low cost [9]. According to the World Instant Noodles Association (WINA), 270 million servings of instant noodles are consumed worldwide each day, with $80 \%$ of total consumption in Asian countries [10]. Instant noodles are consumed in more than 80 countries worldwide; China has the highest consumption of instant noodles, followed by Indonesia, Japan, and Vietnam [10].

In many Asian countries, noodles have been a staple food for centuries. Instant noodles are made from wheat flour, starch, water, salt, or kansui (an alkaline mixture of sodium carbonate, potassium carbonate and sodium phosphate), and other ingredients are added to improve the texture and flavour of the noodles [11]. Convenience, prolonged shelf life, taste, and low price make noodles highly popular. They can be eaten as a snack, as a meal or part of a meal, and some people consume them more than once a day.

According to $\mathrm{Fu}$ [12], salt is used in the production of instant noodles at concentrations of 1-3\% of flour weight, for the purpose of strengthening and tightening the gluten protein of the dough. Salt also serves to reduce cooking time, enhance flavour, provide a softer and more elastic texture, and inhibit enzyme activities and growth of microorganisms [12]. In addition, salt is a major component of the seasoning sachet that is generally included in the packaging of instant noodles and added at the time of consumption.

Despite the widespread consumption of instant noodles in many countries, there has been relatively little assessment of their impact related to total nutritional intake and health. Analysis of dietary data collected in the Korean National Health and Nutrition Examination Survey (KNHANES) III, 2005, identified that consumers of instant noodles, compared to people who did not consume instant noodles, had significantly higher intakes of energy, fat, sodium, thiamine, and riboflavin and lower intakes of protein, calcium, phosphorus, iron, potassium, vitamin A, niacin, and vitamin C [13]. Analysis from KNHANES IV (2007-2009) demonstrated that the consumption of instant noodles two or more times per week was associated with a higher prevalence of metabolic syndrome in women (OR: 1.68; 95\% CI: 1.10, 2.55) and that this association was independent of major dietary patterns [14].

Given emerging data of this kind, reformulation of instant noodles is important to reduce their potentially harmful nutritional composition. Programs to engage with the food industry have been undertaken by many countries worldwide, with some countries already, reporting an impact [15]. However, few countries have set targets specifically for instant noodles to date. The United Kingdom (UK) has set an average target of $200 \mathrm{mg}$ of sodium and a maximum of $350 \mathrm{mg}$ of sodium per $100 \mathrm{~g}$ of instant noodles "as prepared" (made up according to manufacturer instructions) [16]. South Africa (SA) set legislative targets of $1500 \mathrm{mg}$ of sodium/100 $\mathrm{g}$ by 2016 and of $800 \mathrm{mg}$ of sodium per $100 \mathrm{~g}$ by 2019 "as sold" [17], similar to the PICs regional target of $1600 \mathrm{mg} / 100$ [18]. "As sold" refers to $100 \mathrm{~g}$ of product before it is made up with water, ready to eat.

Through the Global Food Monitoring Group (GFMG) [19], the George Institute for Global Health has been supporting countries to establish comprehensive food composition databases (FCDs) to monitor the nutritional composition of packaged food, which can be used to drive national and international improvements to the food supply, and improve the health of billions of people worldwide. 
The aim of this analysis was to assess sodium levels in instant noodles using data from the GFMG national databases as well as from countries that have recently collected sodium data for instant noodles as part of shop surveys. The mean values and ranges of sodium content of instant noodles were compared, both within and between countries, and sodium content was compared against existing sodium targets for instant noodles [16-18]. The purpose of the analysis was to compare the sodium content of instant noodles sold worldwide to monitor sodium levels against existing targets and to identify opportunities to reformulate instant noodles as a means to reduce population level salt consumption.

\section{Materials and Methods}

Data on instant noodles collected between 2012 and 2016 were extracted from existing packaged food composition databases from countries that are part of the Global Food Monitoring Group (GFMG) [19]. Data on instant noodles were also gathered from countries that have recently been supported by the George Institute to gather shop survey data as part of surveillance activities to monitor sodium contents of the food supply (Table 1). All data were collected systematically by trained research assistants in accordance with the GFMG protocol. Data from the respective databases included brand name, product name, pack size, serving size, sodium mg/100 g "as sold", sodium mg/100 g "as prepared", salt g/100 g "as sold", and salt g/100 g "as prepared".

Table 1. Proportion of instant noodles collected per country and average pack/serving size (g).

\begin{tabular}{|c|c|c|c|c|c|c|c|c|c|c|c|}
\hline \multirow{2}{*}{$\begin{array}{l}\text { Date of } \\
\text { Data } \\
\text { Collection }\end{array}$} & \multirow[t]{2}{*}{ Data Source } & \multirow[t]{2}{*}{ Country } & \multirow{2}{*}{$\begin{array}{l}\text { Total No. of } \\
\text { Products } \\
\text { Collected }\end{array}$} & \multicolumn{2}{|c|}{$\begin{array}{l}\text { Products with } \\
\text { Sodium Data }\end{array}$} & \multicolumn{2}{|c|}{$\begin{array}{l}\text { Products with } \\
\text { Sodium Data } \\
\text { "as Sold" }\end{array}$} & \multicolumn{2}{|c|}{$\begin{array}{l}\text { Products with } \\
\text { Sodium Data } \\
\text { "as Prepared" }\end{array}$} & \multirow[t]{2}{*}{$\begin{array}{c}\text { Average } \\
\text { Pack Size (g) }\end{array}$} & \multirow{2}{*}{$\begin{array}{l}\text { Average Serving } \\
\text { Size (g) as } \\
\text { Prepared }\end{array}$} \\
\hline & & & & $n$ & $\%$ & $n$ & $\%$ & $n$ & $\%$ & & \\
\hline 2015 & FCD & New Zealand & 85 & 83 & 98 & 42 & 51 & 41 & 49 & 87 & 343 \\
\hline 2014 & FCD & Australia & 58 & 58 & 100 & 9 & 16 & 49 & 84 & 86 & 308 \\
\hline 2015 & FCD & China & 283 & 283 & 100 & 283 & 100 & 0 & 0 & 98 & - \\
\hline 2013 & Shop survey & Fiji & 28 & 28 & 100 & 23 & 82 & 5 & 18 & 69 & 143 \\
\hline 2015 & Shop survey & Indonesia & 28 & 28 & 100 & 28 & 100 & 0 & 0 & 76 & - \\
\hline \multirow[t]{2}{*}{2013} & FCD & Costa Rica & 18 & 18 & 100 & 18 & 100 & 0 & 0 & 57 & - \\
\hline & Totals & & 765 & 725 * & 95 & 485 & 67 & 240 & 33 & 78 & 275 \\
\hline
\end{tabular}

- data not available.* Products that listed sodium or salt information, but did not state if as sold or as prepared were excluded from further analysis $(n=5)$.

\subsection{Data Categorisation}

Instant noodles were defined according to Codex Alimentarius [20], as packaged noodles, with or without additional seasonings provided in separate pouches, ready for consumption after rehydration. Data was categorised into two main groups: "as sold" or "as prepared" according to the listed nutrition information. Products categorised "as sold" listed sodium information based on dry weight including the seasoning. Products that were categorised "as prepared" listed sodium information based on the product as prepared for consumption according to manufacturer instructions, for example, "add $x$ millilitres of water" and included an addition of the seasoning in the sodium value.

\subsection{Data Analysis}

The total number of instant noodle products and the number of products with sodium or salt information was recorded for each country. Sodium content was calculated from salt where salt information alone was provided on the packaging, using the conversion factor of $\mathrm{Na}(\mathrm{mg})=\mathrm{salt}(\mathrm{mg})$ $(\mathrm{NaCl}) / 2.5$. The mean, median, and ranges of sodium $(\mathrm{mg} / 100 \mathrm{~g})$ were calculated for each category ("as sold" and "as prepared") for each country. Average pack size, "as sold", and average portion size, "as prepared", were derived from available data as given on pack for each country. Mean sodium values of instant noodle products reporting sodium "as sold" were compared against the SA and PICS regional targets, while those reporting sodium "as prepared" were compared against the UK 2017 targets. 
The salt targets were converted to sodium for ease of comparison where necessary. The proportion of products known to meet the sodium targets were derived for each country. The contribution of an average packet of instant noodles to the WHO's recommended intake of $<2000 \mathrm{mg}$ of sodium (5 g salt) per day was derived using mean sodium values and average pack size for each country.

Sub-analyses comparing sodium content of noodles of countries by income level (based on The World Bank's list of economies [21]) and by whether or not they had specific sodium targets in place for instant noodles were conducted. Median sodium content (mg/100) was compared using the Wilcoxon rank-sum test. The proportion of products meeting the target between groups was compared using the chi-square test. A $p$-value of $<0.05$ was considered significant.

\section{Results}

Data were collated on 765 instant noodles products from 10 countries. China had the greatest number of noodle products (283 products, 37\% total), followed by the UK (137, 18\%), New Zealand $(85,11 \%)$, and Australia (58,8\%). Indonesia and Costa Rica had the fewest products, 28 and 18 products respectively (Table 1 ).

\subsection{Labelling}

Five percent of products did not list sodium or salt content on the nutrition information panel; the majority of these were from India. Sixty-eight percent of instant noodle products in India did not provide sodium content information. Of all the products that did display sodium information, approximately $67 \%$ of products listed nutrition information "as sold", while $33 \%$ listed nutrition information "as prepared" (Table 1). Most (92\%) of the noodle products from the UK listed nutrition information "as prepared", compared to China, Indonesia, India, and Costa Rica, which all listed the nutrition information "as sold". In Australia and New Zealand, 84\% and 49\%, respectively, of noodle products listed their nutritional content "as prepared".

\subsection{Range and Levels of Sodium Per $100 \mathrm{~g}$}

There was a wide range in sodium content of instant noodles within and between countries, and the distribution of sodium was not normal, so median sodium values were also reported (Table 2). The highest mean and median sodium content (mg/100 g) of instant noodles "as sold" was found in products in China (mean 1944, median 2062, IQR 757, range 397-3678) followed by Australia, Fiji, Samoa, and Indonesia. The lowest mean sodium content (mg/100 g) was found in products in New Zealand (mean 798, median 508, IQR 429, range 249-2380).

The highest mean sodium content (mg/100 g) of instant noodles "as prepared" was for products in New Zealand (mean 388, median 360, IQR 106, range 222-725), whilst the lowest mean sodium content (mg/100 g) "as prepared" was for products in the UK (mean 220, median 200, IQR 100, range 120-440).

\subsection{Percentage of Products which Meet Targets}

Forty percent of all products met the PICs targets for instant noodles (1600 mg/100 g "as sold"); 37\% met SA 2016 targets (1500 mg/100 g "as sold") and 72\% met the UK 2017 maximum target (350 mg of sodium/100 g "as prepared"). Among countries with targets, 26\% and 39\% of instant noodles in Fiji and Samoa, respectively, met the PICs regional salt targets; $86 \%$ of products in SA met the SA salt targets, and $90 \%$ of products in the UK met the UK 2017 salt targets.

Sub-analysis comparing countries with sodium targets (either "as sold" or "as prepared") against countries without targets in place showed that countries with targets for instant noodles had a significantly higher proportion of instant noodle products meeting the targets. The proportion of products meeting the PICs, SA, and UK targets in countries with salt targets for instant noodles compared to those without targets were $56 \%$ vs. $36 \%(p=0.001), 47 \%$ vs. $34 \%(p=0.031)$, and $86 \%$ vs. $49 \%(p<0.001)$, respectively. 


\subsection{Average Pack Size}

There were large variations in both pack sizes and serving sizes. Average pack size ranged from $57 \mathrm{~g}$ in Costa Rica to $98 \mathrm{~g}$ in China. Where serving size information was given, average serving size, "as prepared", ranged from $143 \mathrm{~g}$ in Fiji to $300 \mathrm{~g}$ in South Africa. Six out of 10 countries provided serving size information on the instant noodles packaging (Table 1). Based on an average packet of noodles "as sold", the estimated average contribution of one packet of noodles towards the World Health Organization daily recommended maximum intake of sodium $(<2000 \mathrm{mg}$ ) ranged from $35 \%$ in India and New Zealand (628 mg per pack and $697 \mathrm{mg}$ per pack, respectively) to $95 \%$ in China (1905 mg per packet in China) (Figure 1).

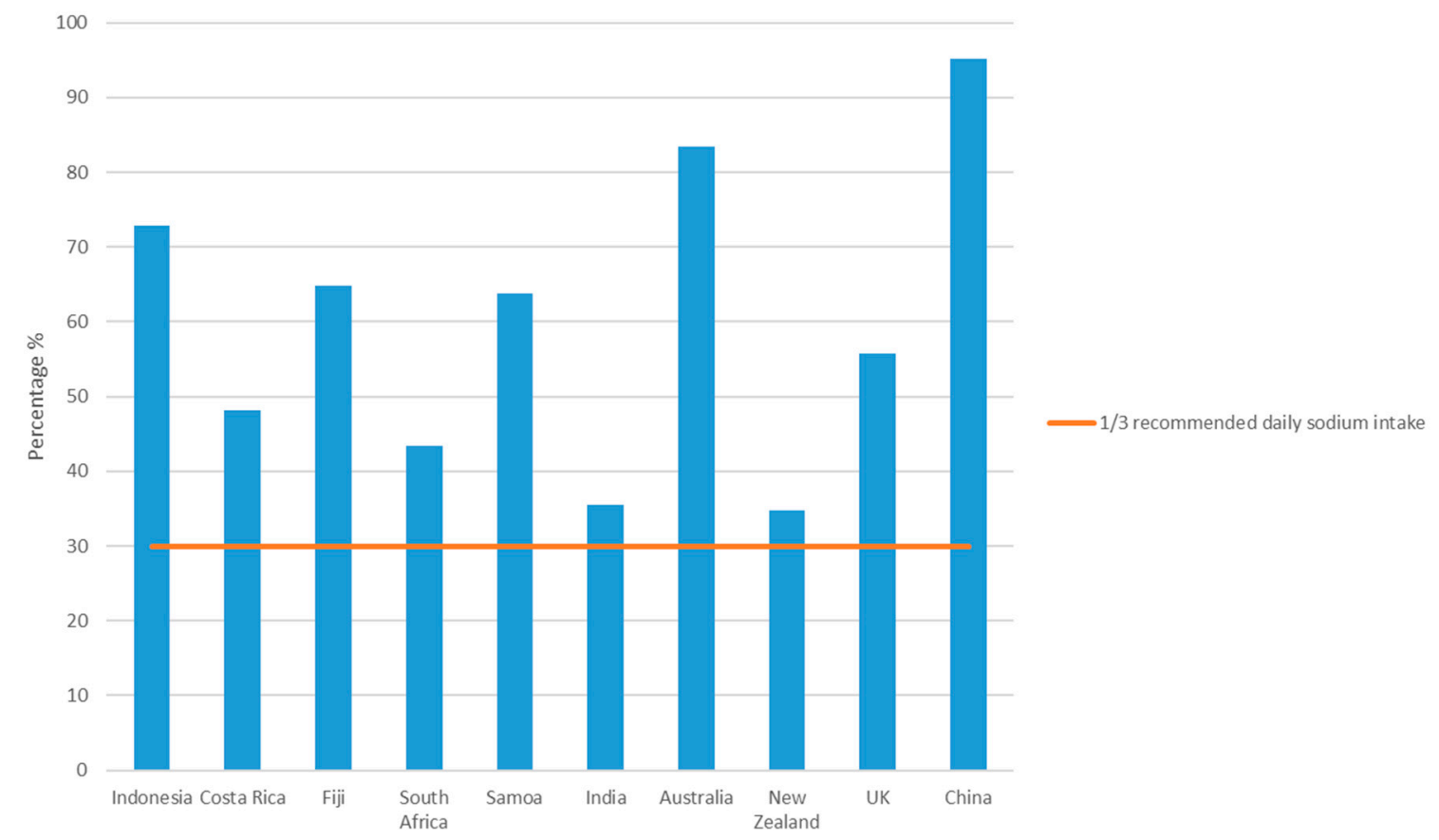

Figure 1. Estimated sodium contribution (\%) of an average packet of instant noodles "as sold" with maximum recommended daily sodium intake (2000 $\mathrm{mg} /$ day).

\subsection{Comparison of Sodium Levels in Instant Noodles between High-Income Countries and} Middle-Income Countries

Seven of the 10 countries included in the analysis were classified as middle-income countries (MICs), and 3 classified as high-income countries (HICs); there was no data from low-income countries. Median sodium level of instant noodles "as sold" were significantly higher in MICs (1889 mg/100 g) compared to HICs $(605 \mathrm{mg} / 100 \mathrm{~g})(p<0.001)$. In addition, a significantly higher proportion of products in HICs compared to MICs met the Pacific Island $(71 \%$ vs. $35 \%, p<0.001)$ and South Africa salt targets ( $71 \%$ vs. $32 \%, p<0.001)$. There was no significant difference for instant noodles with mean sodium levels "as prepared". 
Table 2. Mean, range, median interquartile range, and percentage of products that meet sodium targets.

\begin{tabular}{|c|c|c|c|c|c|c|c|c|c|c|c|c|c|c|}
\hline \multirow{3}{*}{$\begin{array}{l}\text { Country (World } \\
\text { Bank Group) }\end{array}$} & \multicolumn{8}{|c|}{ Products with Sodium Data "as Sold" } & \multicolumn{6}{|c|}{ Products with Sodium Data "as Prepared" } \\
\hline & \multirow[t]{2}{*}{$n$} & \multirow{2}{*}{$\begin{array}{l}\text { Mean } \\
\text { Sodium } \\
(\mathrm{mg} / 100 \mathrm{~g}) \\
\text { as Sold }\end{array}$} & \multirow{2}{*}{$\begin{array}{l}\text { Range of } \\
\text { Sodium } \\
(\mathrm{mg} / 100 \mathrm{~g}) \\
\text { as Sold }\end{array}$} & \multirow{2}{*}{$\begin{array}{l}\text { Median } \\
\text { Sodium and } \\
\text { IQR }(\mathrm{mg} / 100 \mathrm{~g}) \\
\text { as Sold }\end{array}$} & \multicolumn{2}{|c|}{$\begin{array}{l}\text { Products Known to } \\
\text { Meet Pacific Salt } \\
\text { Reduction Target } \\
\text { (1600 mg/100 g as Sold) }\end{array}$} & \multicolumn{2}{|c|}{$\begin{array}{c}\text { Products Known to } \\
\text { Meet South Africa } \\
2016 \text { Target } \\
\text { (1500 mg/100 g as Sold) }\end{array}$} & \multirow[t]{2}{*}{$n$} & \multirow{2}{*}{$\begin{array}{c}\text { Mean } \\
\text { Sodium } \\
\text { (mg/100 g) as } \\
\text { Prepared }\end{array}$} & \multirow[t]{2}{*}{$\begin{array}{c}\text { Range } \\
(\mathrm{mg} / 100 \mathrm{~g}) \text { as } \\
\text { Prepared }\end{array}$} & \multirow{2}{*}{$\begin{array}{l}\text { Median } \\
\text { Sodium and } \\
\text { IQR }(\mathrm{mg} / 100 \mathrm{~g}) \\
\text { as Prepared }\end{array}$} & \multicolumn{2}{|c|}{$\begin{array}{c}\text { Products Known to Mee } \\
\text { UK } 2017 \text { Max Sodium } \\
\text { Target ( } 350 \mathrm{mg} / 100 \mathrm{~g} \\
\text { as Consumed) }\end{array}$} \\
\hline & & & & & $n$ & $\%$ & $n$ & $\%$ & & & & & $n$ & $\%$ \\
\hline New Zealand (HIC) & 42 & 798 & $249-2380$ & $508(429)$ & 35 & 83 & 35 & 83 & 41 & 388 & $222-725$ & $360(106)$ & 19 & 46 \\
\hline UK (HIC) & 11 & 1323 & $488-2650$ & 948 (1620) & 6 & 55 & 6 & 55 & 121 & 220 & $120-440$ & $200(100)$ & 109 & 90 \\
\hline Australia (HIC) & 9 & 1939 & $950-3050$ & $2110(951)$ & 3 & 33 & 3 & 33 & 49 & 378 & $205-635$ & $350(181)$ & 25 & 51 \\
\hline China (MIC) & 283 & 1944 & $397-3678$ & 2062 (757) & 74 & 26 & 67 & 24 & 0 & - & - & - & - & - \\
\hline Samoa (MIC) & 28 & 1854 & $970-3360$ & 1751 (610) & 11 & 39 & 6 & 21 & 15 & 334 & $245-590$ & $280(75)$ & 12 & 80 \\
\hline Indonesia (MIC) & 28 & 1916 & $770-7584$ & 1388 (1025) & 15 & 54 & 15 & 54 & 0 & - & - & - & - & - \\
\hline South Africa (MIC) & 28 & 1206 & $350-1640$ & $1314(202)$ & 27 & 96 & 24 & 86 & 9 & 331 & $266-475$ & $290(90)$ & 5 & 56 \\
\hline Fiji (MIC) & 23 & 1892 & $845-3510$ & $1913(767)$ & 6 & 26 & 6 & 26 & 5 & 317 & $200-443$ & 300 (184) & 3 & 60 \\
\hline Costa Rica (MIC) & 18 & 1703 & $1148-2278$ & 1766 (242) & 4 & 22 & 4 & 22 & 0 & - & - & - & - & - \\
\hline India (MIC) & 15 & 910 & $280-1932$ & 590 (1067) & 12 & 80 & 12 & 80 & 0 & - & - & - & - & - \\
\hline HICs sub-total & 62 & 1057 & $249-3050$ & $605(1280)$ * & 44 & $71^{*}$ & 44 & $71^{*}$ & 211 & 289 & $120-725$ & $270(180)$ & 153 & 73 \\
\hline MICs subtotal & 423 & 1838 & $280-7584$ & $1889(926)$ & 149 & 35 & 134 & 32 & 29 & 330 & 200-590 & $290(98)$ & 20 & 69 \\
\hline Totals & 485 & 1738 & 249-7584 & 1823 (1029) & 193 & 40 & 178 & 37 & 240 & 294 & $120-725$ & $273(160)$ & 173 & 72 \\
\hline
\end{tabular}

* Difference between HICs and MICs significant at $p<0.001$. - data not available. 


\section{Discussion}

This assessment of the sodium content of 765 instant noodles products from 10 countries demonstrated extremely wide variation in sodium content, both between and within countries, according to product ranges and brands. The huge variations in mean sodium content of products in different countries clearly demonstrates significant potential to reduce the sodium content of noodles sold worldwide.

Reasons for the wide range of sodium content of instant noodles between countries cannot be explained solely by taste preferences of consumers, as there were also vast differences in the sodium levels of the instant noodles on the market within each country. For example, the sodium content of instant noodles in Australia ranged from $950 \mathrm{mg} / 100 \mathrm{~g}$ to $3050 \mathrm{mg} / 100 \mathrm{~g}$ ("as sold"), with the highest sodium instant noodle product containing over 3 times more sodium than the lowest sodium instant noodle product. This shows clearly that manufacturers are able to produce instant noodles with far less sodium and that these products are already accepted by consumers. This is evidence that reformulation of instant noodles is feasible, both technologically as well as from a consumer acceptability perspective. Similar results were observed looking at the analyses of median values, which confirms the main findings.

Whilst recognising that the targets only apply to the countries or regions in which they were set, the fact that the sodium content of instant noodles was consistently lower in countries with targets demonstrates the effectiveness of targets as a public policy tool. For example, China, which has the highest number of instant noodle products, does not have targets for sodium levels in foods, and had the lowest proportion of instant noodle products meeting international targets. However, there is scope for greater compliance, as not all products within countries with targets, met the targets, which points toward the need for more concerted efforts to reduce salt by the food industry. This highlights the importance of monitoring frameworks to allow for the transparent and objective evaluation of the food industry towards meeting the targets. In Fiji and Samoa for example, only $39 \%$ and $26 \%$ of products, respectively, met the PICS regional targets. The targets are part of a voluntary framework in Fiji and are being incorporated into regulations that have yet to be implemented in Samoa. Most Pacific Island countries are also highly dependent on imports, which means they need to work with food importing companies as well as local manufacturers to implement targets and highlights the importance of strong government leadership to support policy implementation. The high level of sodium in instant noodles coupled with their popularity provides a strong case for sodium reduction targets for instant noodles in all countries.

Both voluntary and legislated sodium reduction targets can lead to industry action to reduce sodium; $90 \%$ of instant noodle products in the UK met the UK targets (which were voluntary targets to be achieved by 2017), and $86 \%$ of products in South Africa met the South African mandatory targets to be achieved by 2016. Public health experts believe that regulation is a much stronger driver for industry reformulation [22], but voluntary programs that are supported by a strong monitoring framework, coupled with strong advocacy efforts, are also making considerable progress [23].

This research also identified that instant noodles in middle-income countries have a significantly higher average sodium content compared to high-income countries. This is of concern, given that nutrition transition is resulting in an increased availability of more ultra-processed foods in these countries [24], and supports the need for robust policies to regulate the food supply to reduce the already overburdened constraints on the healthcare system due to poor diet.

Further to the need for reformulation of instant noodles to contain less sodium, this study highlights the need for clear and consistent nutrition information panels (NIPs) to enable consumers to make healthier food choices. In India, $68 \%$ of products did not list sodium data on nutrition information panels, thus failing to meet International Codex Alimentarius requirements [25]. The Food Standards and Safety Authority of India does not currently require reporting of sodium content on food packaging [26]. This lack of nutrition information not only inhibits consumers from making informed choices about food purchases but also prevents any monitoring and evaluation of the food supply. 
The fact that some instant noodle manufacturers label sodium information on nutrition information panels "as sold" while others label sodium "as prepared" (as prepared according to manufacturer instructions) within the same country further complicates the picture for both consumers and policy makers. In New Zealand, for example, almost half of the products labelled sodium information "as sold" and half "as prepared". This creates potential confusion for consumers at the point of purchase and makes it difficult to compare nutrition information between brands. Almost a third of all instant noodle products analysed labelled sodium information "as prepared" according to manufacturer instructions. Consumers may not necessarily follow manufacturers' instructions in preparation of the product, which introduces further potential bias in estimates and makes it more difficult for consumers to moderate salt intakes. In countries with interpretive front of pack labelling, for example, the colour coded Front of pack (FOP) nutrition labelling scheme in the UK [27], there is an opportunity for these systems to signpost healthier alternatives and make direct comparisons between products easier for consumers at the point of purchase.

Inconsistent pack sizes provide an additional challenge; the results from this survey showed that pack sizes ranged from $57 \mathrm{~g}$ in Costa Rica to $97 \mathrm{~g}$ in China and that manufacturers did not always quantify a recommended serve size. A single packet of one brand of instant noodles in China contributes almost the entire (95\%) WHO recommended maximum $<2000 \mathrm{mg}$ of sodium/day. In Indonesia, Fiji, or Samoa, the average packet of noodles would contribute almost two-thirds of this amount, whereas in India and New Zealand consumers would consume almost one-third.

Ensuring that instant noodles are reformulated to reduce sodium and labelled in a meaningful way is even more important given the fact that they are increasingly being promoted as a vehicle for micronutrient fortification, either added through the flour used to make the product or to the seasoning powders consumed with the noodles [28,29]. This practice may result in contradictory public health outcomes.

There were some limitations to the study. The number of products available in the ultra-processed packaged food composition database may not necessarily reflect the number of products sold in a particular country, but rather those that were captured during shop surveys undertaken within a limited subset of retail outlets, at specific time points. Products were categorised "as sold" or "as prepared" according to the investigators' best interpretation, using mean sodium as a guide. Products that could not be categorised were excluded from further analysis. Products were collected in shop surveys between 2012 and 2016 and may no longer be on sale due to stock changes, and sales data could not be corroborated to assess market share of particular brands. However, the data obtained provides a clear indication of the high levels of sodium in these popular products, which supports the need for reformulation efforts worldwide to reduce sodium in instant noodles to the lowest possible level.

\section{Conclusions}

The high level of sodium in instant noodles across the world is a major public health concern, given their low cost, convenience, and widespread availability, and the fact that high sodium levels are a key contributor to ill health. There is a need for clear targets coupled with rigorous reformulation efforts to reduce the amount of sodium added to instant noodles. Better regulation of the sodium content of commonly consumed ultra-processed foods is key to reducing population-level salt consumption around the world.

Acknowledgments: This work was supported by a number of organisations listed below as part of the Global Food Monitoring Group (GFMG) and independently by providing data for the survey: Costa Rican Institute of Research and Education on Nutrition and Health (INCIENSA); Discover Vitality, South Africa; The George Institute for Global Health, Australia; The NCD Asia Pacific Alliance, Japan; The Pacific Research Centre for the Prevention of Obesity and Non-communicable Diseases (C-POND), Fiji; The National Institute for Health Innovation, University of Auckland, New Zealand; World Action on Salt and Health, London; Pacific Technical Support Unit, World Health Organization, Fiji; Ministry of Health, Samoa. 
Author Contributions: C.F., J.W. and K.C. conceived of the study; M.C. facilitated access to the data; C.F. and J.S. analyzed the data; C.F. drafted the paper. All authors reviewed and provided written comments on subsequent drafts.

Conflicts of Interest: J.W. is Director of the World Health Organization Collaborating Centre on Population Salt Reduction and is supported by a joint National Health and Medical Research Council and National Heart Foundation Career Development Fellowship and receives additional funding from the World Health Organization and Victorian Health Promotion Foundation. All other authors declare no conflict of interest.

\section{References}

1. Global Status Report on Noncommunicable Diseases; World Health Organization: Geneva, Switzerland, 2014.

2. Wang, G.; Labarthe, D. The cost-effectiveness of interventions designed to reduce sodium intake. J. Hypertens. 2011, 29, 1693-1699. [CrossRef] [PubMed]

3. Global Action Plan for the Prevention and Control of Noncommunicable Diseases 2013-2020; World Health Organization: Geneva, Switzerland, 2013.

4. He, F.J.; MacGregor, G.A. Reducing population salt intake worldwide: From evidence to implementation. Progr. Cardiovasc. Dis. 2010, 52, 363-382. [CrossRef] [PubMed]

5. Jaenke, R.; Barzi, F.; McMahon, E.; Webster, J.; Brimblecombe, J. Consumer Acceptance of Reformulated Food Products: A Systematic Review and Meta-analysis of Salt-reduced Foods. Crit. Rev. Food Sci. Nutr. 2017, 57, 3357-3372. [CrossRef] [PubMed]

6. Charlton, K.E.; Langford, K.; Kaldor, J. Innovative and Collaborative Strategies to Reduce Population-Wide Sodium Intake. Curr. Nutr. Rep. 2015, 4, 279-289. [CrossRef]

7. Popkin, B.M.; Adair, L.S.; Ng, S.W. Global nutrition transition and the pandemic of obesity in developing countries. Nutr. Rev. 2012, 70, 3-21. [CrossRef] [PubMed]

8. Monteiro, C.A.; Moubarac, J.C.; Cannon, G.; Ng, S.W.; Popkin, B. Ultra-processed products are becoming dominant in the global food system. Obes. Rev. 2013, 14, 21-28. [CrossRef]

9. Gulia, N.; Dhaka, V.; Khatkar, B.S. Instant Noodles: Processing, Quality, and Nutritional Aspects. Crit. Rev. Food Sci. Nutr. 2014, 54, 1386-1399. [CrossRef] [PubMed]

10. World Instant Noodles Association. Global Report; World Instant Noodles Association: Tokyo, Japan, 2016.

11. Kim, S.G. Instant noodles. In Pasta and Noodle Technology; Kruger, J.H., Matsuo, R.B., Dick, J.W., Eds.; American Association of Cereal Chemistry: St. Paul, MN, USA, 1996; pp. 195-225.

12. Fu, B.X. Asian noodles: History, classification, raw materials and processing. Food Res. Int. 2008, 41, 888-902. [CrossRef]

13. Park, J.; Lee, J.S.; Jang, Y.A.; Chung, H.R.; Kim, J. A comparison of food and nutrient intake between instant noodle consumers and non-instant noodle consumers in Korean adults. Nutr. Res. Prac. 2011, 5, 443-449. [CrossRef] [PubMed]

14. Shin, H.J.; Cho, E.; Lee, H.J.; Fung, T.T.; Rimm, E.; Rosner, B.; Manson, J.E.; Wheelan, K.; Hu, F.B. Instant noodle intake and dietary patterns are associated with distinct cardiometabolic risk factors in Korea. J. Nutr. 2014, 144, 1247-1255. [CrossRef] [PubMed]

15. Webster, J.; Trieu, K.; Dunford, E.; Hawkes, C. Target Salt 2025: A Global Overview of National Programs to Encourage the Food Industry to Reduce Salt in Foods. Nutrients 2014, 6, 3274-3287. [CrossRef] [PubMed]

16. Public Health Responsibility Deal: UK Salt Reduction Targets for 2017; UK Department of Health: London, UK, 2014.

17. Government Gazette: No. R. 214 Foodstuffs, Cosmetics and Disinfectants Act, 1972 (Act 54 of 1972) Regulations Relating to the Reduction of Sodium in Certain Foodstuffs and Related Matters The Heart and Stroke Foundation South Africa; South Africa Government: Pretoria, South Africa, 2013.

18. Pacific Salt Reduction Targets: Why Setting Targets for Salt in Food? Western Pacific Region; World Health Organization: Geneva, Switzerland, 2014.

19. Dunford, E.; Webster, J.; Metzler, A.B.; Czernichow, S.; Ni Mhurchu, C.; Wolmarans, P.; Snowdon, W.; L'Abbe, M.; Li, N.; et al. Maulik PK International collaborative project to compare and monitor the nutritional composition of processed foods. Eur. J. Prev. Cardiol. 2012, 19, 1326-1332. [CrossRef] [PubMed]

20. CODEX Alimentarius: Standard for Instant Noodles CODEX STAN 249-2006; Food and Agriculture Organization of the United Nations and World Health Organization: Rome, Italy, 2016. 
21. The World Bank. World Bank List of economies (December 2016). Available online: https://datahelpdesk. worldbank.org/knowledgebase/articles/906519-world-bank-country-and-lending-groups (accessed on 5 June 2017).

22. Moodie, R.; Stuckler, D.; Monteiro, C.; Sheron, N.; Neal, B.; Thamarangsi, T.; Lincoln, P.; Casswell, S. Profits and pandemics: Prevention of harmful effects of tobacco, alcohol, and ultra-processed food and drink industries. Lancet 2013, 381, 670-679. [CrossRef]

23. Charlton, K.E.; Webster, J.; Kowai, P. To Legislate or Not to Legislate? A Comparison of the UK and South African Approaches to the Development and Implementation of the Salt Reduction Programs Nutrients. Nutrients 2014, 6, 3672. [CrossRef] [PubMed]

24. Popkin, B.M. The nutrition transition and obesity in the developing world. J. Nutr. 2001, 131, 871S-873S. [PubMed]

25. CODEX Alimentarius: Guidelines on Nutrition Labelling; Food and Agriculture Organization of the United Nations and World Health Organization: Rome, Italy, 2011.

26. Food Safety and Standards (Packaging and Labelling) Regulations; Food Safety and Standards Authority of India (FSSAI): New Delhi, India, 2011.

27. Guide to Creating a Front of Pack (FoP) Nutrition Label for Pre-Packed Products Sold Through Retail Outlets. In Obesity and Healthy Eating Divison; Department of Health: London, UK, 2013.

28. Kim, S.K. Overview of the Korean noodle industry. Food Sci. Biotechnol. 1997, 6, 125-130.

29. Spohrer, R.; Larson, M.; Maurin, C.; Laillou, A.; Capanzana, M.; Garrett, G.S. The growing importance of staple foods and condiments used as ingredients in the food industry and implications for large-scale food fortification programs in Southeast Asia. Food Nutr. Bull. 2013, 34, S50-S61. [CrossRef] [PubMed]

(C) 2017 by the authors. Licensee MDPI, Basel, Switzerland. This article is an open access article distributed under the terms and conditions of the Creative Commons Attribution (CC BY) license (http:/ / creativecommons.org/licenses/by/4.0/). 